\title{
Greywater recycling and reuse
}

Book or Report Section

Accepted Version

Hyde, K. and Smith, M. (2018) Greywater recycling and reuse. In: Charlesworth, S. M. and Booth, C. A. (eds.) Urban Pollution: Science and Management. Wiley, pp. 211-222. ISBN 9781119260509 doi: https://doi.org/10.1002/9781119260493 Available at https://centaur.reading.ac.uk/85832/

It is advisable to refer to the publisher's version if you intend to cite from the work. See Guidance on citing.

To link to this article DOI: http://dx.doi.org/10.1002/9781119260493

Publisher: Wiley

All outputs in CentAUR are protected by Intellectual Property Rights law, including copyright law. Copyright and IPR is retained by the creators or other copyright holders. Terms and conditions for use of this material are defined in the End User Agreement.

\section{$\underline{\text { www.reading.ac.uk/centaur }}$}

\section{CentAUR}

Central Archive at the University of Reading

Reading's research outputs online 


\section{Chapter 16}

\section{Greywater Recycling and Reuse}

\section{Katherine Hyde and Matthew Smith}

\subsection{Introduction}

The generation of greywater from human bathing and washing is as ubiquitous as the generation of sewage. Untreated or 'raw' greywater is a wastewater that is relatively lightly loaded in organic pollutants, and commonly comprises approximately one third of all human wastewater arising in many developed countries. In traditional and existing drainage systems in the built environment, either inside or outside of properties, all untreated greywater is combined and mixed with more polluted wastewaters flowing into the sewer. More polluted wastewaters can include sewage and faecal matter from toilets, dishwasher discharges, food waste, garage drainage, oils, and other effluents. Due to this mixing of wastewaters, the sewage causes degradation in the quality of the less polluted greywater.

The opportunity to separate out the less polluted greywater is thus foregone. This standard practice means that any original volumes of untreated greywater subsequently require more intensive treatment at the wastewater treatment plant (WTP) than they would have done had they not been discharged into the mixed sewer environment. In many respects, it may be significantly more environmentally prudent, $\mathrm{CO}_{2}$ emission reducing, and resilience enhancing to maintain the separation between polluted sewage and less polluted greywater flows.

Furthermore, as more greywater is treated, recycled, and reused, the volume of pristine mains water required for basic functions such as toilet flushing and garden watering is 
reduced (see Hatfield et al., 2014). This leads to better overall urban water cycle efficiency, and in certain circumstances, may also lead to carbon savings and system cost reductions. Unfortunately, influencing changes in wastewater system configurations is currently not predicated in strategy and policy in the water industry at local or national levels.

There is an option for utilising greywater for irrigation, and this has potential for sustaining green infrastructure during times of drought. While this principle achieves wide, cursory acceptance and would be unlikely to be rejected during an intensely dry period, significant barriers exist to regular irrigation using greywater.

\subsection{The Ubiquitous Nature of Pollutants in Wastewater from Baths, Showers, and}

\section{Handbasins}

So far, it is assumed that all wastewater from bathrooms remains in the piped urban environment, whether being discharged to the foul sewer or being recycled in a building's plumbing system.

In fact, it is not necessarily an environmental offence to discharge small volumes of treated bathroom greywater directly to the environment, provided they are not polluting. For example, treated effluent from a septic tank or a small sewage treatment plant can be discharged into the environment as long as the discharge point does not lie in a Source Protection Zone 1, and is less than 15,000 litres per day (EA, 2016).

This approach allows treated greywater to be applied to kitchen gardens, orchards, allotments, and so on. Clearly, this must be carefully controlled because any exceedances of limits and quality standards would attract a legal warning and possibly a penalty or fine from the Environment Agency. Legality under pollution prevention legislation and regulations depends on the greywater source, nature, and volume/ flow characteristics (see 
Section 16.9). Furthermore, the concept of discharging untreated greywater directly to the environment for the purpose of irrigating green infrastructure might sometimes be seen as unpalatable in environmental quality terms, even if the pollutant concentrations in the discharge are low. Visual and sensory observations, such as smell, colour, and clarity may occasionally be useful as an 'early warning indicators', but are rarely accurate or scientific.

One of the practical problems is that if, for example, a basic in-line filter is installed to treat discharges of shower and bath water, it may not be possible to monitor the quality of the treated greywater. In order to reach a reliable view about treated water quality and compliance with standards and regulations, appropriate monitoring and recording equipment is essential. There is a range of equipment available from basic monitors for $\mathrm{pH}$, to more competent monitoring and recording instruments. Even the lowly $\mathrm{pH}$ measurement, when taken on a regular basis, can assist the householder in becoming familiarised with the performance of a basic filter. In some cases, this may be sufficient to alert the homeowner about the start of deterioration in the normal performance of the filter, thus triggering maintenance checks and remediation.

One of the reasons for raising this important question is that, in cases where chemical and microbiological analysis has been undertaken, the analysis demonstrates the degree of safety in discharging the treated greywater into the environment. Finley et al. (2009) found no significant difference in contamination levels between crops irrigated with tap water, untreated greywater, and treated greywater. They stated that faecal coliform levels and faecal streptococcus levels were highest on carrots and lettuce leaves, respectively, but that contamination for all the crops they tested were low, and constituted an insignificant health risk. 


\subsection{The Quality of Untreated Greywater and Its Water Resource Value}

The integration of physical and environmental sciences combined with socioeconomic factors and socio-technological behaviours and practices is fundamentally influential when considering anthropogenic engagement in greywater recycling and reuse.

Human engagement may often exhibit polarised reactions, in the form of enthusiastic alignment with the principles and with the environmental benefits gained through the recycling of water. In contrast, disengagement may be observed, for example, in the inherent right of access to pristine water for all needs, or because water is "free" (rain arrives without any payment), and therefore, wastage of water appears to some degree, to be inconsequential. Possibly more complex reactions present unwillingness to use recycled greywater based upon religious reasons, or upon health or safety concerns (Hyde et al., 2016). These views are largely founded upon perception, though often scientifically quantifiable.

For this reason, it is becoming more pressing to engage with customers about the sharing of information on water quality. In future, as customers become more familiar with water quality parameters such as acidity and alkalinity, nitrate $\left(\mathrm{NO}_{3}\right)$, biochemical oxygen demand (BOD), and more, there is likely to be increased dialogue between customers concerning water quality results and suppliers.

\subsection{Greywater Terminologies Used in This Chapter}

One important point of terminology relates to definitions of different greywater flows. Most importantly, all existing flows from handbasins, baths, and showers comprise untreated greywater at their point of discharge to the collecting waste pipes. In this 
chapter, the use of the term 'treated greywater' is used as consistently as possible to distinguish it from greywater that has not been treated, filtered, or chlorinated.

\subsection{Pollutants in Untreated Greywater}

The quality of greywater relates directly to the source from which the greywater originated and the uses to which it has been put. In some cases, relatively clean handwash water may often contain few other constituents than the water from tap(s), the surface dirt and bacteria from hands, the dispensed hand soap or steriliser, and other common constituents from the use of handbasins. Some of the cleaning products used for cleaning the utilities and floors, and the wastewater from the cleaning regimes in bathrooms will be disposed of either via the waste pipe(s) from the handbasins, or alternatively via the toilets themselves. Circumstantial evidence regarding bathroom behaviour has been noted but has to be excluded from rigorous data collection and analysis, which tends to suggest a wider range of these kinds of behaviours than might be gathered from available primary data. Commonly, this is private, and good data are rarely available. To provide one example, babies and clothes might be bathed and washed respectively in handbasins, an activity that is likely to give rise to higher levels of bacteria in the basin wastewater. This leads to one important observation about raw greywater, which is that, while assumptions about the average pollutant levels of a typical raw greywater from one specific location in one specific building may be reasonable, the actual distribution and frequency of variation in the pollutant concentrations can rarely be assumed. They can be predicted only in generalities, or after data sampling and analysis at specific sites.

On the other hand, since any waste stream may demonstrate consistently low pollutant concentrations after being subjected to a robust treatment process, so may be the case with greywater. Indeed, this is what is required to make greywater resources increasingly 
useful, by producing a known, reliable, and acceptable water quality. This is further explored in Section 16.6.

Shower and bath wastewater give rise to pollutants of the types already mentioned and also exhibit a range of constituents and concentrations from bath oils, shampoos, skin beauty treatments, hair and hair dyes, to pharmaceutical preparations, medical and wound treatments, and small solid objects. In some buildings, muddy clothes and outer garments are washed in bathrooms. Also, dust and substances from various trades such as brick and plaster dust, paint, agricultural dusts, liquid treatments used in any trade including pesticides and repellents, oils, grease, and fuels, and many other substances may be encountered. Many workers in trades do not return from site to the office at the end of their working day, and consequently, washing and showering at home introduces these typical occupational contaminants into greywater. Without further evidence, it might be assumed that such pollutant concentrations arising could be relatively low.

A number of basic tests can be conducted to check the variability of certain key quality characteristics of any greywater. Although it is preferable to know the concentrations of a full range of quality parameters of the greywater being discharged, on a routine basis this very often has to be reduced to a few parameters that can be monitored easily by the use of hand-held probes and indicator solutions. Most domestic greywaters are not 'regulated' (Environmental Permitting Regulations, 2010), in the sense that they are not required by UK regulations to be tested daily or weekly according to a frequent and specific timetable, and there is no requirement to keep daily quality records. Where discharges are regulated, there is likely to be a more rigorous regime in place.

In experiments using greywater, some authors such as Sawadogo et al. (2014) have used untreated rather than treated greywater, while others such as Pinto et al. (2010) and Christova-Boal et al. (1996) have tested various categories of greywater, which can lead to 
misunderstanding of what greywater actually is. Wiel-Shafran et al. (2006) tested greywater that included a significant proportion of laundry detergent solution, typical of washing machine wash cycles. Washing powders and solutions often contain aggressive ingredients, and as a consequence, some of the greywater currently recycled in the United Kingdom excludes laundry detergents. Most recently published studies have focused on greywater collected only from handbasins, baths, and showers, thus excluding greywater obtained from washing machines. In summary, this is a critical differentiator since studies using only bathroom and handbasin greywater will derive their results from greywaters containing lower concentrations of surfactants and salts than are used in washing machines. Avoiding the use of wastewater from kitchen sinks ('sullage') avoids problems associated with, for example, the accumulation of fats, oils, and greases, known in the water industry as F.O.Gs. At a local scale, it is theoretically possible for households to control their own greywater quality by controlling the volumes of water used for showers, baths, and handbasins, and by controlling the amounts of soap and other personal hygiene products that are used. In practice, this requires procedures usually too onerous for an average household to control on a regular basis.

\subsection{Standardising Greywater Treatment Systems: Removing and Minimising Pollutant Concentrations}

When designing systems for treating and recycling greywater, the quality of the untreated greywater should be assumed to be contaminated, in the absence of definitive data. The terminology used in this chapter follows, as far as possible, that set out in BS: 8525 Parts 1 and 2 (2010 and 2011, respectively).

In order to facilitate discussions about wider reuse, greywater treatment will be discussed, reviewed, and evaluated where it is relevant to the development of integrated urban systems. Underlying the scientific approach is the general baseline assumption that 
greywater contains more pollutants than 'clean' water. In the United Kingdom, clean water is usually taken to be piped mains water delivered to consumers at potable and drinking water standards for human consumption.

There are a number of attributes of greywater quality and greywater supply that require scrutiny before greywater can be recycled, treated, and reused. Some of the pollutants found in greywater are also present in mains water, although usually at lower concentrations in the latter. For this reason, the reference term 'constituents' will be used in preference to 'pollutants', wherever they are occurring in a controlled environment such as an in-building water system. This will be explained according to the principles of constituent concentration profiles, whereby a range of concentrations is measured during longitudinal studies, for example, while being compared to the variability of a number of other factors. Once outside the built environment, greywater starts to mix with other sources of water, and here, greywater constituents are generally more accurately described as pollutants.

The Environment Agency's guidance (EA, 2016) requires an environmental risk assessment to be undertaken as a critical precursor prior to any greywater discharge. While the specific pathways for particular discharges of treated greywater must be subjected to individual assessment, in the EA guidance (2016), the following points have been noted in relation to the discharge of domestic greywaters. First, sensitive receptors must be identified and a risk assessment undertaken. Receptors include any places used to grow food, or to farm animals or fish; fields and allotments used to grow food; drain and sewer systems; local groundwater protection zones or Nitrate Protection Zones; homes or groups of homes; private drinking water supplies; schools, hospitals, or other public buildings; playing fields and playgrounds; conservation and habitat protection areas, including Sites of Special Scientific Interest (SSSIs); ponds, streams, rivers, lakes, and the sea. Second, 
although a treated greywater is likely to be of good quality, there should be no hesitation in comparing its constituents with those specified for the minimum requirements for treated sewage or trade effluents when the discharge compliance arrangements are being considered. In these cases, risks to surface water from hazardous pollutants, risks from "sanitary" and other pollutants, and risks to groundwater must all be considered (EA, 2010).

Third, once the potential receptors have been identified, the applicant has to state what the potentially consequential risks are; these include uncontrolled, unexpected, and unintended emissions as well as regular and frequent discharges. Where no such risks are relevant to the circumstances, the applicant must state that they are not relevant and may have to provide substantiating evidence, which may include an exercise to screen out potential risks (further details given in Section 16.9) by testing whether the discharges are likely to be of acceptable environmental standards or discharge limits. Constituents arising from washing and bathing include personal care products as sold over the counter. These might broadly present a similar toxicological risk to those encountered during product use itself, although the concentrations of exposure and incidental mixtures with other pollutants will be different. Personal care products sold in the United Kingdom provide details of the ranked order of constituents according to proportion, from the highest to the lowest, but rarely provide specific concentrations. The allowable discharge concentration for each substance or determinand to achieve 'no deterioration' in the environment must be calculated by the applicant. This condition for achieving no deterioration is not optional. Each applicant must calculate or determine appropriate limits for the discharge that are environmentally protective, technically feasible, and whose cost is proportional to potential benefits. For new discharges, the overall polluting load must be managed so that no individual concentration of ammonia, phosphorus, or BOD increases. Where this is not 
feasible or cost-effective, the Environment Agency may allow a within-class deterioration of up to $10 \%$. Applicants for new discharges must be very careful to check that recent surface water quality concentrations have not improved since figures were last published, leading to potentially unexpected water quality impacts.

Personal care products must not contain substances that are pathogenic or capable of producing disease. Thus, they are manufactured by including either bacteriocidal or bacteriostatic constituents so that the product is not capable of supporting the proliferation or transference of bacteria. However, one pollutant of note due to increasing evidence of its environmental persistence in wastewaters is Triclosan, a bacteriocide commonly included as an ingredient in cleaning and personal care products (Ricart, 2010).

\subsection{Managing the Environmental Characteristics, Applications and Urban Uses of Treated Greywater, and Urban Uses}

Sawadogo et al. (2014) conducted tests and evaluations on plant growth during irrigation with untreated greywater. They focused on irrigation using laundry water at low, medium, and high concentrations of detergent, whereby the highest concentration was a worst-case scenario in comparison with concentrations normally found in greywater from baths and showers. The high concentrations of detergent produced adverse effects, causing death in both lettuce and okra, whereas medium to low concentrations produced between low to nodiscernible effects. Wiel-Shafran et al. (2006) reported that irrigation using insufficiently treated greywater is 'mistakenly considered safe'. They suggested that known surfactant concentrations in greywater range from 0.7 to $70 \mathrm{mgL}^{-1}$ and that accumulation in soils can cause hydrophobia in soils, thus affecting soil productivity.

However, both Wiel-Shafran et al. (2006) and Lado and Ben-Hur (2009) (2009) state that lightly loaded greywaters are more reliable in terms of avoiding potentially damaging, 
unwanted polluting effects for crops and soils. Thus, if the inorganic and organic loading of greywater can be reduced by treatment, then that is likely to lead to less significant effects on crops. Further research is needed to determine the appropriate extent of treatment required for greywater from different sources that results in a quality which reduces adverse impacts and encourage crop growth.

Sawadogo et al. (2014) reported that surfactants in irrigation waters containing detergents have been recognised as a major contributor in the reduction of hydraulic conductivity of soils. In the cases of irrigation water with higher detergent concentrations, more advanced soil degradation can occur, leading to water-repellent soils. Lado and Ben-Hur (2009) showed that these have negative impacts on agricultural productivity and environmental sustainability. The question of the application of dilute greywaters for sustaining green infrastructure appears less widely understood.

Pinto et al. (2010) reported the key chemical characteristics of potable and greywater quality used in their irrigation and growth trials of silverbeet, over a period of 60 days (see Table 16.1).

Table 16.1. Greywater and tap water quality used in irrigation and growth trials (Pinto et al., 2010).

\begin{tabular}{|l|l|l|l|l|}
\hline Sample & $\mathrm{pH}$ & $\begin{array}{l}\text { Electrical conductivity } \\
\mu \mathrm{S} / \mathrm{cm}\end{array}$ & Total nitrogen, mg/L & Total phosphate, mg/L \\
\hline Greywater & 10.5 & 1358.0 & 0.2 & 4.4 \\
\hline Potable & 7.0 & 277.0 & 0.16 & 0.0 \\
\hline
\end{tabular}

Christova-Boal et al. (1996) applied greywater with a $\mathrm{pH}$ in excess of 8.0 during some of their growth tests. The authors observed that greywater has the potential to increase the soil alkalinity if applied to gardens for a long period. Pinto et al. (2010) reported pH results in excess of 10.0 and described the phytotoxicity arising from greywater reuse as being principally due to anionic surfactants altering rhizosphere microbial communities. Such 
phytotoxicity effects arising from greywater reuse demonstrate significant variability of impact according to plant species.

In Table 16.2, the authors Sawadogo et al. (2014) provided electrical conductivity (EC) results in comparison to low, normal, and high concentrations of surfactant, expressed in terms of $\mathrm{mgL}^{-1}$ of linear alkylbenzene sulphonate (LAS). Of those three surfactant compositions, the greywater applied in Pinto et al. (2010) aligns approximately with the EC of the normal concentration surfactant used in Sawadogo et al. (2014). In the latter case, the $\mathrm{pH}, 9.9$, of the normal concentration surfactant also lies in a reasonably comparable range to the $\mathrm{pH} 10.5$ greywater applied by Pinto et al. (2010). The increasing concentrations of detergent LAS gave rise to increasing $\mathrm{pH}$ and $\mathrm{EC}$ values, as well as increasing the values of total $\mathrm{N}, \mathrm{C}$, and $\mathrm{P}$.

Table 16.2. Constituents in greywater tests (Sawadogo et al., 2014).

\begin{tabular}{|l|c|l|l|l|}
\hline Watering & $\begin{array}{l}\text { Distilled } \\
\text { water }\end{array}$ & $\begin{array}{l}\text { Low } \\
\text { concentration } \\
\text { surfactant, } \\
0.1 \mathrm{~g} \mathrm{~L}^{-1}\end{array}$ & $\begin{array}{l}\text { Normal } \\
\text { concentration } \\
\text { surfactant, } \\
1.0 \mathrm{~g} \mathrm{~L}^{-1}\end{array}$ & $\begin{array}{l}\text { High } \\
\text { concentration } \\
\text { surfactant, } \\
5.0 \mathrm{~g} \mathrm{~L}^{-1}\end{array}$ \\
\hline $\mathrm{pH}$ & 6.1 & 9.9 & 10.2 \\
\hline $\mathrm{EC}\left(\mathrm{mS} \mathrm{cm}^{-1}\right)$ & 28 & 159 & 1082 & 4870 \\
\hline $\begin{array}{l}\text { Detergent as } \\
\text { LAS }\left(\mathrm{mg} \mathrm{L}^{-1}\right)\end{array}$ & $\mathrm{ND}$ & 13.5 & 135.6 & 678 \\
\hline $\mathrm{N}_{\text {total }}\left(\mathrm{mg} \mathrm{L}^{-1}\right)$ & $\mathrm{ND}$ & 0.01 & 0.12 & 6.6 \\
\hline $\mathrm{C}_{\text {total }}\left(\mathrm{mg} \mathrm{L}^{-1}\right)$ & $\mathrm{ND}$ & 15.3 & 153 & 765.1 \\
\hline $\mathrm{P}_{\text {total }}\left(\mathrm{mg} \mathrm{L}^{-1}\right)$ & $\mathrm{ND}$ & 13.2 & 132.3 & 661.6 \\
\hline
\end{tabular}

LAS = linear alkylbenzene sulphonate; $\mathrm{ND}=$ not detected $; \mathrm{EC}=$ electrical conductivity.

16.7 University of Reading's 2016 Experimental Irrigation of Sedum using Treated

\section{Greywater}

The University of Reading monitored growth trials of sedum grown in floor-standing boxes irrigated using bathroom greywater for a 6-month period during 2015-2016. The statistical mean values calculated from six-months of data are shown in Table 16.3. Irrigation was conducted using untreated greywater, treated greywater, and a mains tap water control. This 
enabled the assessment of analytical variables that were likely to produce any potential growth effects to be specifically attributed to irrigation. The chemical characteristics of the greywater were based on the British Standard 'recipe' for synthetic test greywater, which constituted a 'lightly loaded' greywater quality according to the EC and TP results, although the TN is significantly higher than the TN used in Pinto et al. (2010).

Table 16.3. Treated greywater and tap water quality monitored from 02 September 2015 to 02 March 2016.

\begin{tabular}{|l|c|c|c|c|}
\hline Sample & $\mathrm{pH}$ & $\begin{array}{l}\text { Electrical } \\
\text { conductivity, } \mu \mathrm{S} / \mathrm{cm}\end{array}$ & $\begin{array}{l}\text { Total nitrogen, } \\
\mathrm{mg} / \mathrm{L}\end{array}$ & $\begin{array}{l}\text { Total phosphate, } \\
\mathrm{mg} / \mathrm{L}\end{array}$ \\
\hline $\begin{array}{l}\text { Treated } \\
\text { greywater }\end{array}$ & 7.6 & 669.9 & 4.5 & 0.02 \\
\hline $\begin{array}{l}\text { Potable } \\
\text { water }\end{array}$ & 7.8 & 520.2 & 0.5 & 0.01 \\
\hline
\end{tabular}

$<\mathrm{P}>$ The potable (mains) water comprised the largest component of the synthetic greywater and so, unsurprisingly for a lightly loaded greywater, the $\mathrm{pH}$ of the tap water and the $\mathrm{pH}$ of the greywater were very similar, as were the phosphate results in both cases. The EC was higher than that of the potable water, which was mainly due to the organic and inorganic loading associated with the presence of surfactants such as detergents or shampoo, as well as the constituents of the treated sewage final effluent (FE). The total nitrogen was also higher in the greywater than in the potable water due to the nitrogen content of the treated sewage effluent included in the synthetic greywater recipe, as well as the surfactants.

Treated sewage effluent was not added because:

1) The synthetic mix required a source of pollutants containing similar components to shower greywater, which follows the UK standard for Bacteriological Examination test procedures that would be difficult or impossible to replicate. 
2) The test procedure needed to challenge the greywater treatment system to demonstrate that higher bacterial loads were safely eradicated from the treated greywater by a satisfactory process.

\subsection{Soil Results Evaluated during Irrigation using Greywater Constituents}

In Sawadogo et al. (2014), the plant growth parameters in okra and lettuce were measured every week, including the dry weights of stems and leaves of all plants. Soil $\mathrm{pH}$ and soil EC tended to increase as the detergent concentrations increased in the irrigation solutions. There were no significant differences in okra fruit growth (fresh and dry weight) using distilled water, low concentration (LC), and normal concentration (NC) treatments. However, plants in $\mathrm{HC}$ treatments died 20 days after planting (DAP). No significant difference was noticed in lettuce shoots (dry weight) between LC, NC, and DW treatments, but lettuce in HC treatments died 12 DAP. EC significantly increased in all the treatment regimes. Laundry detergent can inhibit plant growth, and the application of greywater containing high concentrations of detergent can increase soil salinity.

In the University of Reading's study, the sedum plants showed a gradual decrease in size and plant health during the winter months which was found regardless of the test category of irrigation water, whether greywater, treated greywater, or mains (potable) water. With the return of average ambient temperatures above approximately $10^{\circ} \mathrm{C}$, the plants in all the irrigation categories and soil types exhibited more leaf growth. In test sedum boxes kept in the greenhouse during the first 1.5 months of the trials, a significant increase in plant development and growth volume was found in comparison with plants grown outside. Subsequently, the greenhouse-grown plants were moved outside in order to compare their performance during UK winter weather conditions with those plants that were already outside. The health of the latter group of plants deteriorated more quickly than that of the plants that had been outside from the beginning of the trials. 
Sodium is an environmental pollutant when it is present at concentrations above

background levels (and in some cases, at concentrations at background levels). Figure 16.1 shows that all plants had similar leaf sodium concentrations at the start of the trials, but this reduced during the first two months and did not subsequently recover.

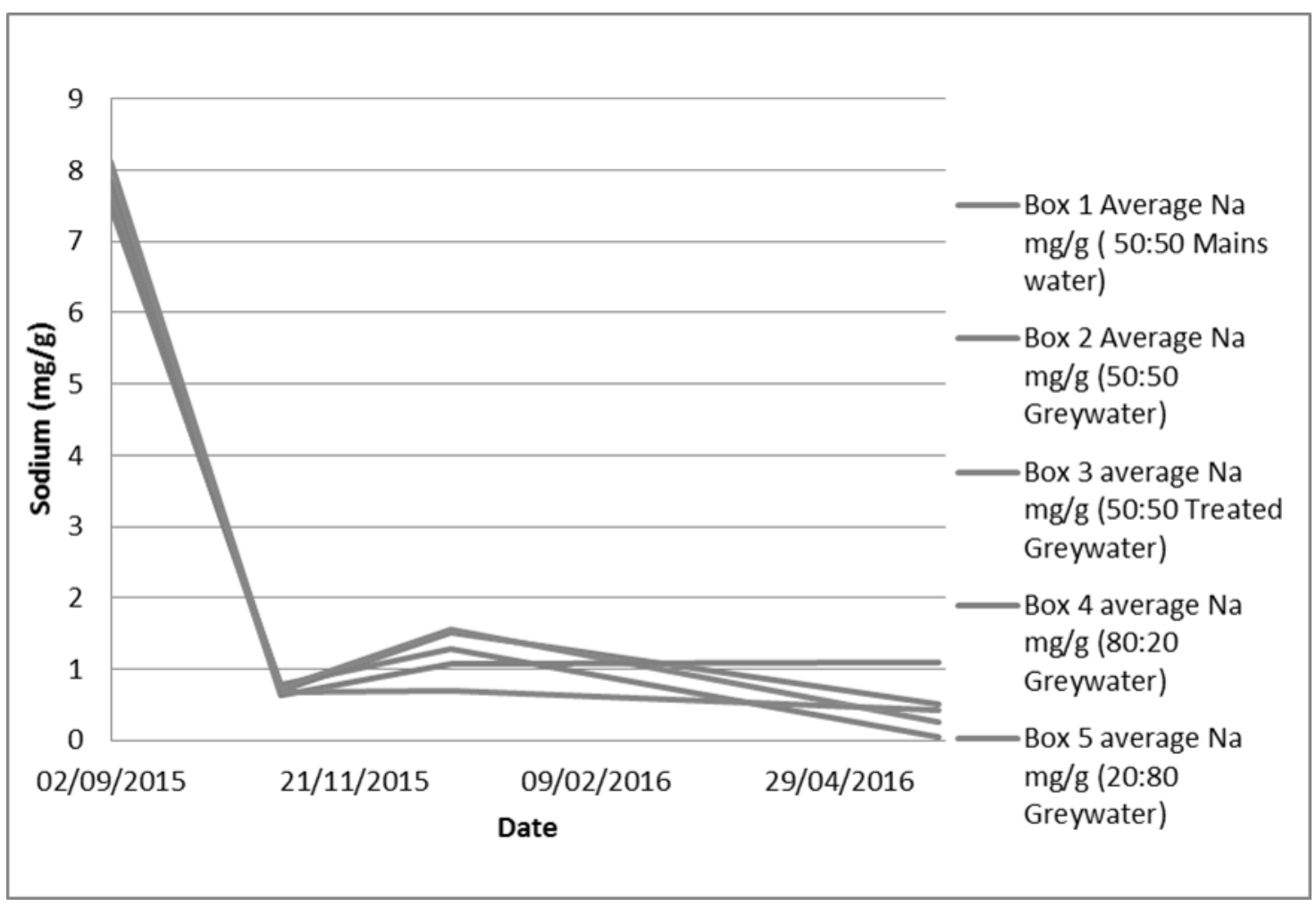

Figure 16.1 < Longitudinal changes in plant leaf sodium concentrations for differing watering regimes; '50:50' refers to a plant substrate of 50 parts growing medium to 50 parts compost; ' $80: 20$ ' refers to a plant substrate of 80 parts growing medium to 20 parts compost; and '20:80' to a plant substrate of 20 parts growing medium to 80 parts compost.

\subsection{Applying the Principles of Controlled Waters to Greywater Discharges for}

\section{Sustaining Green Infrastructure}

Evidence from studies reviewed in this chapter has established that greywater can affect crops and other plants when higher concentrations of detergent are applied, at the highest limit even causing plant death. The evidence from the Reading trials demonstrated that 
impacts from watering sedum using dilute greywater gave rise to only limited impacts during a winter period when the plants were stressed due to low ambient temperatures. If significantly less impacts arising from low concentrations of detergent could be demonstrated, consideration would then be given to the concept of allowing treated greywaters to be used for watering green infrastructure. The Environment Agency (EA) (2016) states that risk assessments are not required for greywater discharges from domestic properties unless:

- a trade discharge is included in the effluent, or

- there is a discharge to ground or surface water of $>15 \mathrm{~m}^{3}$ per day, or

- the discharge to ground is more than $2 \mathrm{~m}^{3}$ per day, and the location is in a groundwater Source Protection Zone, SPZ1 (an area of highest risk to groundwater quality).

The EA (2016) also does not require screening tests if the water is discharged to the same river or groundwater that the water was originally taken from or if no hazardous pollutants are added to the water. This is potentially of assistance to small greywater discharges that contain no hazardous pollutants, since the greywater discharge could potentially support green infrastructure in the same area of the catchment.

The stages required for screening for a particular discharge include:

- Identification of the pollutants released from the greywater treatment plant or source

- Gathering data on the environmental impacts of the pollutants prior to screening

- Undertaking the screening itself 
This is likely to apply to discharges of greywater containing surfactants. Pollutants must be measured if they are hazardous and released to freshwaters, estuaries, and coastal waters, or to sewers. EA (2016) specifies that pollutants could be present in the discharge if:

1) They have been detected by chemical analysis.

2) They are allowed to be added to the discharge (e.g. water company trade effluent consent or discharges from installations).

3) They have been added to the discharge by means of a treatment process (e.g. using iron or aluminium to remove phosphorus).

Membrane greywater treatment systems (Hatfield et al., 2014) do not introduce chemicals into the greywater as part of the treatment process; thus, its quality, once treated could therefore comply with EA requirements. However, bathing and personal hygiene products in greywater may require routine testing to demonstrate that the greywater is of a suitable quality for reuse.

The average flow rates, times, and duration of discharge, for example, 12 hours per day, will be required to be stated for assessing and monitoring compliance. The risks arising at the site are assessed, including the risks of the discharge creating environmental pollution and the sources of the risks. The assessment steps required by EA (2016) include:

1. Identification of the receptors at risk from the site (people, animals, property, etc.)

2. Identification of the possible pathways from the sources of the risks to the receptors

3. Assessment of the relevant risks to the specific activity; check that they are acceptable

4. Statement of the plans for controlling the risks if they are unacceptably high 
The risk assessment must be submitted as part of a permit application, and a copy must be included in the management system. The criteria for unsatisfactory overflows include operating a breach of permit conditions and/or causing a breach of water quality standards and other regulatory standards EA (2016).

\subsection{Concluding Comments and Review}

Separating greywater before it combines with sewage and laundry effluents can be used to sustain urban environments and their green infrastructure by irrigating using treated greywater. An analytical approach to the quality and reuse opportunities for greywater leads to the determination of water reuse and irrigation potential, feasibility, and water stewardship. The evidence from various studies shows that lightly loaded greywaters can probably be used with confidence for watering certain types of green infrastructure. This is an important potential means for sustaining vegetation during times of water stress or drought.

For larger volume discharges, affordable system configurations for achieving licensable discharges to support plants need to be identified and approved. For smaller, domestic-scale discharges, it appears that there is often little legislative barrier to direct irrigation using treated greywater.

Rationalisation of the technology configuration, and thus the potential costs to be incurred, will provide an opportunity to carefully design and implement landscaping specifically to work in conjunction with irrigation systems. This will reduce levels of pollutants entering the urban environment while establishing and developing the opportunity for more greywater sources to be utilised in a sustainable manner. 


\section{Acknowledgements}

1. European funding from Climate-KIC is acknowledged. The study sponsors had no involvement in the study design, collection, analysis, and interpretation of data or in the writing of the manuscript.

2. The EA, United Kingdom, for extracts from www.environment-agency.gov.uk.

\section{$<$ HA $>$ References}

<REFS>Christova-Boal, D., Eden, R.E., and Mcfarlane, S. (1996) An investigation into greywater reuse for urban residential properties. Desalination, 106, 391-397.

CIRIA. (2015) The SuDS Manual.

http://www.ciria.org/Memberships/The_SuDs_Manual_C753_Chapters.aspx

Environment Agency. (2016) Risk Assessments for Your Environmental Permit;

Environmental Management-Guidance. First published 1 February 2016.

\section{https://www.gov.uk/guidance/risk-assessments-for-your-environmental-permit}

Environmental Permitting Regulations 2010 relate to the regulation of discharges to controlled waters; The Environmental Permitting (England and Wales) Regulations 2010 No. 675. Hansard.

Finley, S., Barrington, S., and Lyew, D. (2009) Reuse of domestic greywater for the irrigation of food crops. Water, Air and Soil Pollution, 199(1), 235-245. doi:10.1007/s11270-008-9874$\mathrm{X}$

Hatfield, E., Booth, C.A., and Charlesworth, S.M. (2014) Greywater harvesting - Reusing, recycling and saving household water. In: Booth, C. and Charlesworth, S.M. (eds.), Water Resources in the Built Environment - Management Issues and Solutions. Wiley Blackwell. 
Hyde, K., Smith, M., and Adeyeye, K. (2016) Developments in the quality of treated greywater supplies for buildings, and associated user perception and acceptance. International Journal of Low-Carbon Technologies, 0, 1-5.

Lado, M. and Ben-Hur, M. (2009) Treated domestic sewage irrigation effects on soil hydraulic properties in arid and semi-arid zones: A review. Soil and Tillage Research, 106 (1), 152-163.

Pinto, U., Maheshwari, B.L., and Grewal, H.S. (2010) Effects of greywater irrigation on plant growth, water use and soil properties. Resources, Conservation and Recycling, 54, 429-435. Ricart, M. et al. (2010) Triclosan persistence through wastewater treatment plants and its potential toxic effects on river biofilms. Aquatic Toxicology, 100 (4), 346-353.

\section{http://dx.doi.org/10.1016/j.aquatox.2010.08.010}

Sawadogo, B., Sou, M., Hijikata, N., Sangare, D., Maiga, A.H., and Funamizu, N. (2014) Effect of detergents from greywater on irrigated plants: Case of Okra (Abelmoschus esculentus) and Lettuce (Lactuca sativa). Journal of Arid Land Studies, 24 (1), 117-120. Wiel-Shafran, A., Ronen, Z., Weisbrod, N., Adar, E., and Gross, A. (2006) Potential changes in soil properties following irrigation with surfactant-rich greywater. Ecological Engineering, $26,348-354$. 